\title{
Inhibitors of human collagenase, MMP1
}

\author{
Sergio Roberto de Andrade Leite \\ Instituto de Química, UNESP, CP 355, 14801-970, Araraquara, SP, Brasil \\ E-mail address: leite@iq.unesp.br
}

\begin{abstract}
Different common drugs (Meloxicam, Tenoxicam and Piroxicam, and sodium alendronate) were tested both experimental and theoretically as inhibitors of interstitial human collagenase, also known as matrix metalloproteinase 1 (MMP-1). The in vitro collagenase activity, alone and in the presence of inhibitors, was quantified by the reaction with a fluorescent synthetic substrate and measuring the change of emission. Collagenase-inhibitor interaction was studied theoretically by computational calculations. Three among the four tested substances showed moderate inhibiting activity against the human collagenase.
\end{abstract}

Keywords: collagenase, MMP-1, human metalloproteinases, inhibitors, docking.

\section{Introduction}

The metalloproteinases of the conjunctive matrix, also known as matrixins or MMP (the acronym of Matrix Metallo Proteinase), constitute a subgroup of the zinc-endoproteases produced by the conjunctive tissue. These enzymes participate in the initial events that result in tissue degradation, both in physiologic and pathologic conditions. They are divided in five groups: 1. collagenases that hydrolyze the collagen, protein resistant to most of the proteases; 2. gelatinases, thus named because they hydrolyze denatured collagen, also known as type IV collagenases, for they also degrade native collagen type IV; 3. stromelysins, originally described as proteoglycanases, but that actually possess a reasonably wide proteolytic activity; 4. PUMP; 5. stromelysin 3. Murphy et al [1] proposed a more complete classification, whose updated version is given below:

1. Collagenases: Interstitial collagenase (MMP-1), Neutrophil collagenase (MMP8), Collagenase 3 (MMP-13), Collagenase 4 (MMP-18).

2. Stromelysins: Stromelysin 1 (MMP-3), Stromelysin 2 (MMP-10), Stromelysin 3 (MMP-
11), No trivial name (MMP-19), Enamelysin (MMP-20).

3. Gelatinases: Gelatinase A (72 kD, MMP-2), Gelatinase B (92 kD, MMP-9).

4. Membrane collagenase: MT1- MMP (MMP14), MT2- MMP (MMP-15), MT3- MMP (MMP-16), MT4- MMP (MMP-17).

5. Others: Matrilysin (MMP-7), Macrophage elastase (MMP-12).

The 3D structures of several MMPs were already determined by $\mathrm{X}$ rays diffraction or by NMR spectroscopy, alone or binding to inhibitors [2]. Inside of the molecule domain responsible for the bond to zinc ion, a very similar sequence exists in all of structure-known zinc proteinases: Ala-Ala-His-Glu-hydrophobic aa-Gly-His [3], in which is believed that the two histidine residues link to the zinc ion [4]. The third bond site is not known in all of the cases, unlike in some other zinc-proteins, as the thermolysin, in which the third bond involves a residue of Glu separated from His by 19 amino acids residues [1].

The activation of the matrix metalloproteinases, that is, the transformation of zymogen into active enzyme, involves the change of the coordination of the zinc with the sulphydril group of a 
cystein residue, for water, which turns the fourth point of coordination of that metal $[3,5]$. Different causes that result in the contact loss between cystein and $\mathrm{Zn}$ can activate the enzyme. In vivo this activation is mediated by plasmin.

The inhibition of MMPs is the opposite effect that modulates the activity of MMPs in the normal organism. In Nature this role is played by a family of inhibitors known as tissue inhibitors of metalloproteinases, TIMP, that are proteins that link to several matrixins, not very selectively, inhibiting them. Besides the tissue inhibitors, the human plasma $\alpha 2$-macroglobulin and related proteins of the plasma of other mammals and of the chicken egg also have inhibiting effect [3].

Besides the natural inhibitors, synthetic inhibitors have been prepared in the sense of obtaining drugs for treatment of pathological processes mediated by such enzymes, or when an unbalance between activation and inhibition of MMPs occurs. Among such pathologies we can mention certain rheumatic processes (osteoarthritis and rheumatoid arthritis), tumor invasion and metastasis, and periodontal disease. Unfortunately, the first generation of those drugs, already submitted to clinical trials, did not result in promising drugs. The main problem is the lack of specificity, difficulty that comes from the similarity among the active sites of the different conjunctive matrix metalloproteinases.

The search of effective and selective synthetic inhibitors has stimulated the study of the structure of matrix metalloproteinases of mammals. Since 1993 different MMP structures have been determined by X-ray diffraction and NMR spectroscopy, free or bound to inhibitors [2,618]. The zinc ion in the active site of MMPs is coordinated by at least two histidine residues, of numbers 218 and 222, through one of the atoms of nitrogen of the imidazol ring. Browner et al. [2] demonstrated that, for the case of the matrilysin, such histidine residues and a third, the 228 , are involved in the coordination of the zinc of the catalytic site, through $\mathrm{N} \varepsilon$ of the ring. A second ion zinc, this one with structural function, is coordinated by other three histidine residues and one of glutamic acid. Similar situation takes place in the stromelysin 1, where the catalytic zinc is coordi- nated by His-201, -205 , and -211 , and the structural zinc by His-151, -166, and -179 [14].

To summarize, metalloproteases from connective tissue of mammals, MMPs, have in common two ions of zinc, one located in the enzyme active site, involved in the catalytic process, and the other with structural function, similar to calcium ions in these enzymes. The catalytic zinc ion binds to three histidine residues and, in the active enzymes, to a molecule of water. The other zinc ion also coordinates to three other residues of histidine and to a fourth residue of another amino acid, which depends on the nature of the enzyme.

The active site zinc in the MMPs acts as a Lewis acid, since it is a good electron acceptor. Thus, it is able to polarize a binding group of the substrate and, as a result, if this group is a base, increases its nucleophilic power. On the other hand, acting as an acid, increases the ability of a group connected to it to suffer the attack of a base. An example of the first type is the molecule of water binding to zinc in the active enzyme, which dissociates under the polarizing effect of $\mathrm{Zn}^{2+}$, even in environments with $\mathrm{pH}$ values not very high, generating a hydroxyl able to attack other molecules. This is the mechanism of action suggested for the carbonic anhydrase, another zinc-enzyme, where the hydroxylic oxygen bound to $\mathrm{Zn}^{2+}$ attacks the carbon of the $\mathrm{CO}_{2}$ and produces bicarbonate, after rearrangement and decomposition of the intermediary species. On the other hand, the mechanism of catalysis by matrix metalloproteases, as the human collagenase, is an example of the second type of mechanism. In this case, the hydrolysis of the amide (peptidic bond) begins by attack of the zinc, as a Lewis acid, on the carbonylic oxygen, polarizing the carbonyl and facilitating the attack of its carbon by the hydroxyl of water linked to zinc. The intermediary, negatively charged, then decomposes into carboxylate and amine.

The synthetic inhibitors of the MMPs obtained until now are substances that bind directly or indirectly to the catalytic zinc ion. They are species containing the groups hydroxamate, carboxylate, sulfydryl, sulfoximine, sulfodiimine, sulfonamide or thiol [2, 3, 19-21]. The study of the interaction of inhibitors with the MMPs, mainly the structure determination of enzyme-inhibitor 
complexes, is essential to understand the structural features relevant for the inhibition. These informations constitute the basis for the rational search of new more potent inhibitors, through Theoretical Chemistry calculations, whose results guide their synthesis.

In the present work some common drugs were tested as inhibitors of the human collagenase MMP-1, both experimental and theoretically. The choice of such drugs, currently employed for other pathologies, was made based on experimental and clinical references [22]. The great advantage in selecting drugs already used in other pathologies is the previous knowledge of their toxicity and safety, checked by the acquired clinical experience.

\section{Experimental methods}

Human collagenase (MMP-1) was purchased from ICN Biomedicals Inc., Livermore, CA, USA. The activity of this enzyme was measured by reaction with the synthetic substrate 7-methoxycoumarin-4-acetyl-Pro-Leu-Gly-Leu$\beta$-(2,4-dinitrophenyl) L-2, 3-diaminopropionyl)Ala-Arg- $\mathrm{NH}_{2}$ (abbreviated Mca-Pro-LeuGly-Leu-Dpa-Ala-Arg-NH ${ }_{2}$, from Sigma-Aldrich Co., Saint Louis, MO, USA). In this compound, the fluorescent emission of methoxycoumarin group is quenched by $2,4-$ dinitrophenyl-amino ring. The hydrolysis of the peptide chain by MMP-1 between the Gly and Leu residues extinguishes this effect and enhances the fluorescence at $394 \mathrm{~nm}$, proportionally to collagenase activity [23].

The reactions were performed in a buffered medium (Tricine $50 \mathrm{mM} \mathrm{pH} 7.5$ ) containing $\mathrm{Ca}^{2+}$ $10 \mathrm{mM}$ and $\mathrm{NaCl} 0,10 \mathrm{M}$, in a total volume of $100 \mu 1$. The MMP- 1 concentration was always 10 $\mathrm{mM}$ and that of fluorogenic reagent varied from 1 to $10 \mu \mathrm{M}$. The fluorescence was measured in a microfluorimeter (Tecan Austria Gesellschaft, Salzburg, Austria), with excitation wavelength at $330 \mathrm{~nm}$ and emission at $394 \mathrm{~nm}$.

The choice of substances for the inhibition tests was based on reports in the literature (experimental or clinical) among common drugs with inhibiting effect upon collagenases. The selected drugs have different structures and pharmacological activities, but all share such supposed inhibiting effect [22]. Four ligands were tested: three oxicans, namely Meloxicam, Tenoxicam and Piroxicam, and sodium alendronate. The IC50 was determined for those that exhibited activity against the enzyme.

\section{Computational methods}

Computational calculations performed were: modeling of the three-dimensional structure of the ligands by energy minimization methods, calculation of electronic and thermodynamics properties and simulation of the interaction between ligands and collagenase active site by a docking procedure. The enzyme structure was obtained from Protein Data Bank (structure 1CGL), determined by X-ray diffraction [24, 25]. This structure refers to collagenase co-crystallized with an inhibitor and informs about the molecule region interacting with the ligands. Calculations were performed on a Compaq AP400 workstation with two processors (Windows software for Classical and Quantum Mechanical energy minimization and molecular dynamics) and on a Silicon Graphics Octane workstation (Unix software for docking and $a b$ initio Quantum Mechanical calculation). For the former the softwares used were: CAChe Worksystem 5.04 for Windows (Fujitsu Systems Business of America, Inc., Beaverton, OR, USA) [26] and HyperChem 4.5 for Windows (Hypercube, Inc., Waterloo, ON, Canada) [27], and for the last First Discovery 1.8 (modules: Glide; Liaison; QSite; Impact) and Jaguar 4.1. for Irix (in other words, SGI Unix) (Schrödinger Inc., Portland, OR, USA) [28].

a) Structure of ligands: Three-dimensional structure of the ligands was determined by energy minimization and molecular dynamics simulated annealing, alternately, many times, to obtain a structure in a lower energy minimum. The calculation was performed by the semiempirical Quantum Mechanical method PM3 [29].

b) Ligand electronic properties: Electronic densities and Mülliken formal charges were ob- 
tained by the same PM3 method, applied on the optimized structures.

c) Ligand-MMP1 docking: First a grid calculation was run in order to determine the area to be searched to dock a ligand to the receptor. In this case, this area corresponds roughly to the enzyme active site. To perform this calculation, we utilized the known structure of the enzyme co-crystallized with an inhibitor. Then, the dock computation generated the more plausible binding modes for the tested ligands. Once located favorable structures and bond conformations, binding energies for ligand-receptor pairs were calculated.

d) Total binding energy ligand-enzyme $\left(\mathrm{E}_{\text {bind }}\right)$ : This calculation associates a Quantum Mechanical (QM) and a Classical Molecular Mechanical (MM) procedures. First, the QM energy of the isolated ligand was calculated by an ab initio Density Functional Theory (DFT) method, utilizing the software Jaguar 4.1 (Schrödinger Inc.). Next, the energy of isolated enzyme was calculated by a mixed QM/MM method, the same $a b$ initio DFT technique for the active site region and a MM procedure with the OPLS-AA force field for the rest of the protein molecule. Finally, the $\mathrm{QM}$ energy of the ligand and the QM/MM energy of the enzyme were subtracted from the QM/MM energy of the complex ligand-enzyme. This last was calculated in the same way that the energy of the enzyme alone.

$\mathrm{E}_{\text {bind }}=\mathrm{E}_{\mathrm{QM} / \mathrm{MM}} \mathrm{cplx}-\mathrm{E}_{\mathrm{QM}} \operatorname{lig}-\mathrm{E}_{\mathrm{QM} / \mathrm{MM}} \mathrm{enz}$

e) Entropy calculation: The entropy of human collagenase, free and bond to ligands, was calculated to test entropic effects in the interaction enzyme-inhibitors. Two entropic components must be considered: the conformational entropy of the polypeptide chain and the ordainment of water molecules around the lateral chains of the amino acid residues [30]. Let us consider first the ordering of water molecules on the surface of the protein. In the case of globular proteins, as the human collagenase, this ordering occurs mainly in the external surface of the coil structure, which is in direct contact with aqueous medium. Any disturbance in this hydration layer, for example, due to interaction of the protein with another protein or with a ligand, decreases such order and increases the entropy associated with it. We can estimate the degree of disturbance by calculating the fraction of surface area of the protein involved in this interaction. We supposed, by hypothesis, that this area is equal to half of the surface area of the ligand. The molecular surface area for enzyme and ligands was calculated by the grid method described by Bodor et al [31], using the atom radii of Gavezotti [32] and implemented by the program ChemPlus [33].

The conformational entropy of the polypeptide chain was calculated as follows. Let us consider the variation of Gibbs energy:

$\Delta \mathrm{G}=\Delta \mathrm{H}-\mathrm{T} \Delta \mathrm{S}$

Rearranging and calculating the partial derivatives in relation to temperature:

$(\partial \mathrm{T} / \partial \mathrm{T}) \Delta \mathrm{S}+\mathrm{T}(\partial \Delta \mathrm{S} / \partial \mathrm{T})=-(\partial \Delta \mathrm{G} / \partial \mathrm{T})+(\partial \Delta \mathrm{H} / \partial \mathrm{T})$

The second parcels of equality, both sides, equals zero, so:

$\Delta S=-(\partial \Delta \mathrm{G} / \partial \mathrm{T})$

Thus, the entropy can be calculated by the expression above, provided that we have the variation of free energy with temperature. This was obtained through a Molecular Dynamics, simulating the heating of the molecule in a certain temperature range. We considered that the total energy of the system varies linearly with temperature and that such energy (sum of potential and kinetics energies) can represent the Gibbs energy of the system. Thus:

$\Delta \mathrm{S}=-\left(\mathrm{E}_{\mathrm{Tf}}-\mathrm{E}_{\mathrm{Ti}}\right) /\left(\mathrm{T}_{\mathrm{f}}-\mathrm{T}_{\mathrm{i}}\right)$

Where $\mathrm{i}$ and $\mathrm{f}$ mean initial and final states. Molecular Dynamics was performed using the module HyperNewton of the software HyperChem [27]. The heating was simulated between 0 and $300 \mathrm{~K}$. The total energy for ligands, enzyme and ligand-enzyme complexes was evaluated by clas- 
sical Molecular Mechanics. The conformational entropy was calculated for the free enzyme, for each ligand and for the ligands bound to the enzyme.

\section{Results and Discussion}

Kinetic parameters for the human collagenase were obtained from the plot of fluorescent emission at $394 \mathrm{~nm}$ versus Mca-Pro-Leu-Gly-Leu-Dpa-Ala-Arg- $\mathrm{NH}_{2}$ concentration in $\mu \mathrm{mol} / 1$. This system displays a standard Michaelis-Menten kinetics with a $\mathrm{V}_{\max }=158$ arbitrary units and $\mathrm{Km}=$ 7,88 $\mu \mathrm{M}$.

Among the tested drugs, all the oxicans inhibited the human collagenase (fig. 1).

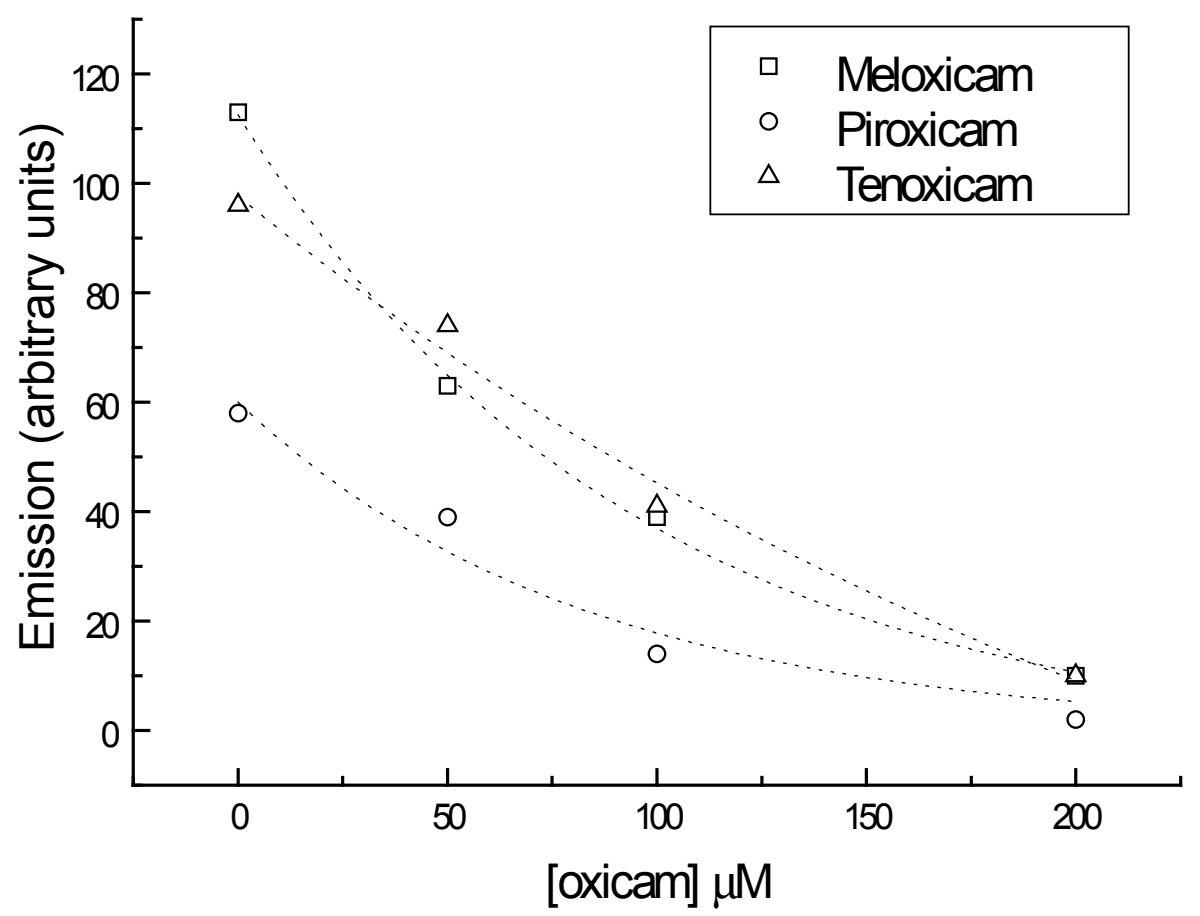

Fig.1 - Effect of oxicans upon activity of human collagenase MMP1, measured by emission at $394 \mathrm{~nm}$ of the Mca-Pro-Leu-Gly-Leu-Dpa-Ala-Arg- $\mathrm{NH}_{2}$ hydrolysis product.

Piroxicam was the most active inhibitor $(\mathrm{IC} 50=63 \mu \mathrm{M})$, followed by Meloxicam $(\mathrm{IC} 50=$ $66 \mu \mathrm{M})$ and Tenoxicam $(\mathrm{IC} 50=91 \mu \mathrm{M})$.

Sodium alendronate, otherwise, enhanced the MMP1 activity (fig. 2). This effect is contradictory with a remark reported in the literature, which describes the inhibiting effect of bisphosphonates upon matrix metalloproteinases [22]. In this work, the authors verified the inhibiting effect of various bisphosphonates on different matrix me- talloproteases of human conjunctive tissue matrix. Although the Alendronate did not inhibit human collagenase, MMP-1, it inhibited the MMPs 3, 8 , 9, 12 and 13. Three other bisphosphonates, Clondronate, Pamidronate and Tilundronate, inhibited the MMP-1. No stimulating or activating effects were observed in any case. On the other hand, we observed a similar activating effect of the alendronate upon the activity of the collagenase produced by the bacterium Clostridium histolyticum, one of the causative agents of gas gangrene [34]. 


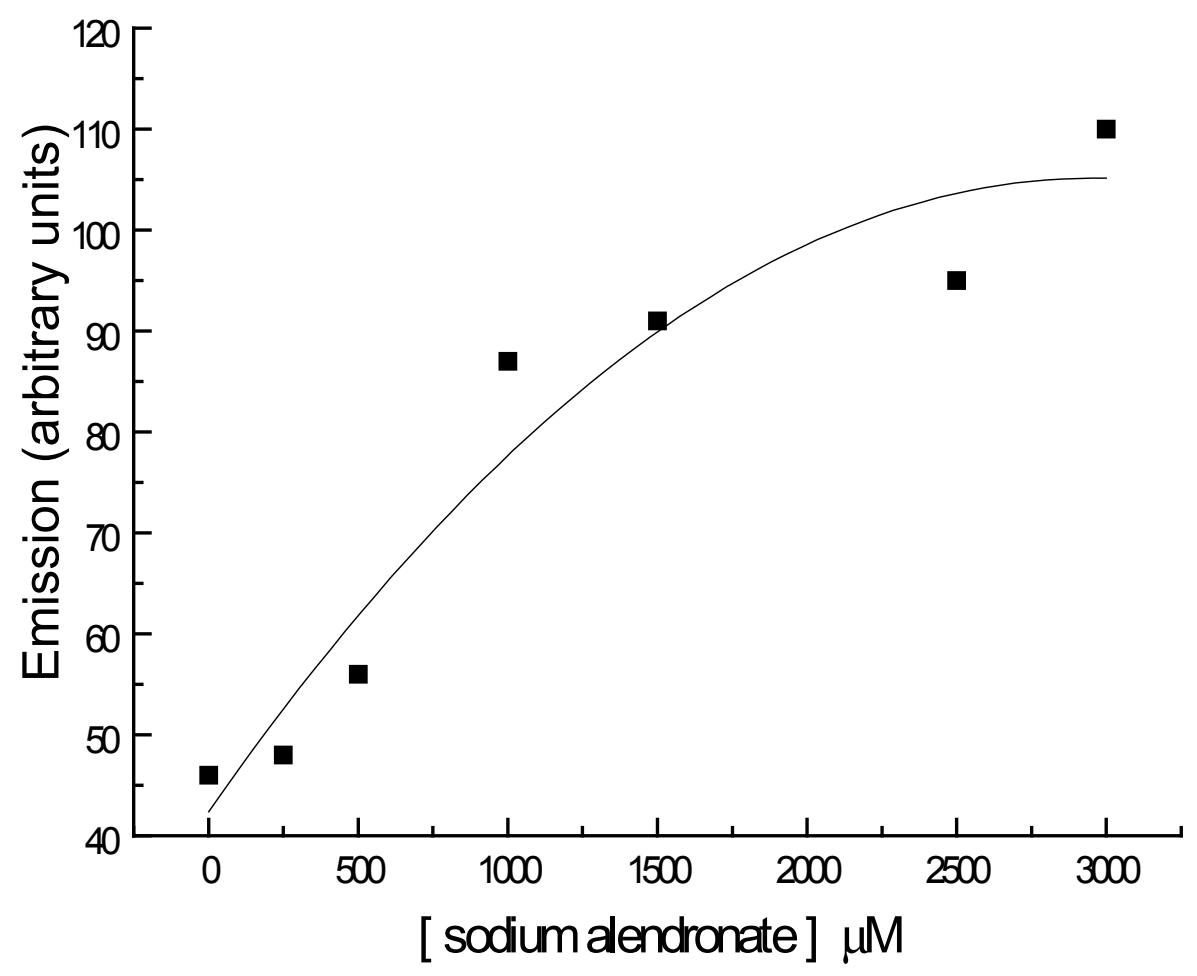

Fig.2 - Effect of sodium alendronate upon activity of human collagenase MMP1, measured by emission at $394 \mathrm{~nm}$ of the Mca-Pro-Leu-Gly-Leu-Dpa-Ala-Arg- $\mathrm{NH}_{2}$ hydrolysis product.

Docking calculations defined the best geometry for ligand-enzyme interaction. The best poses between each ligand and collagenase active site were select. As example, figure 3 shows Piroxicam, the best inhibitor among the tested oxicans, bound to MMP-1 active site. 


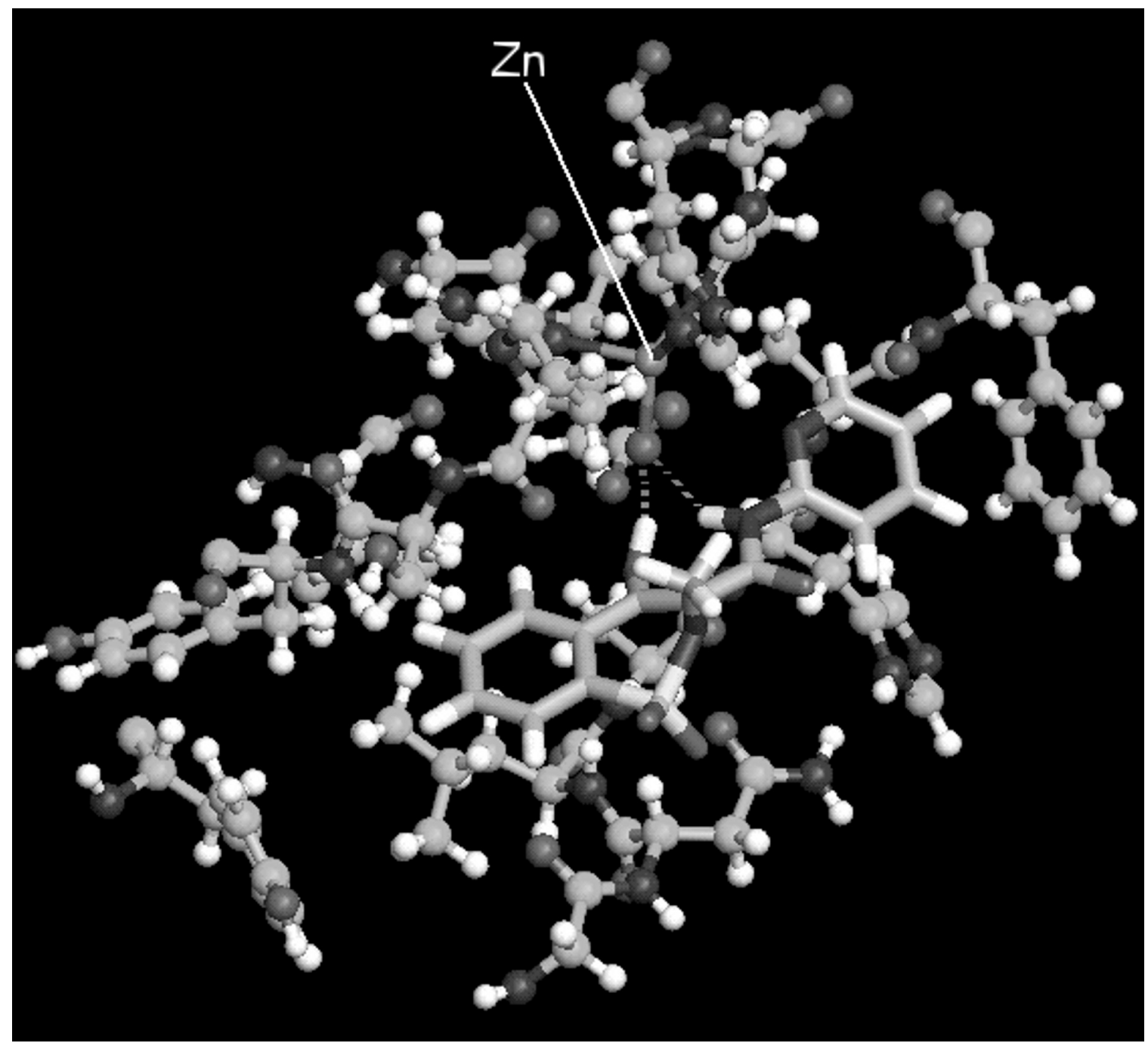

Fig. 3 - Piroxicam bound to human collagenase active site.

Note the two hydrogen bonds between the ligand and the oxygen bound to catalytic $\mathrm{Zn}^{2+}$.

Such simulation suggests the probable chemical interactions between the oxicans and the MMP1 active site. All of them bind through hydrogen bonds to the oxygen coordinated to the catalytic zinc (fig. 4). 
a) Piroxicam Detail:
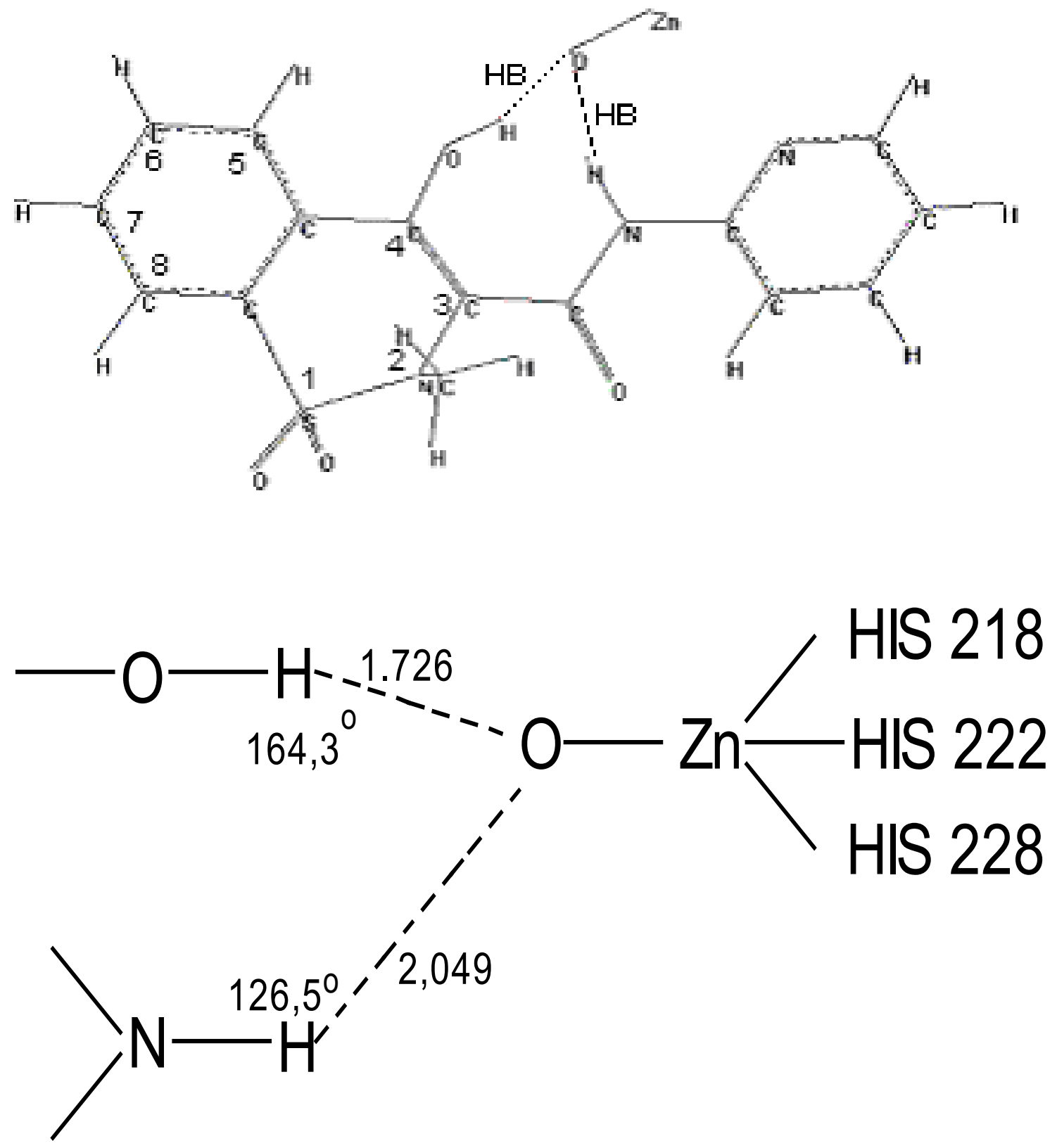
b) Meloxicam Detail:
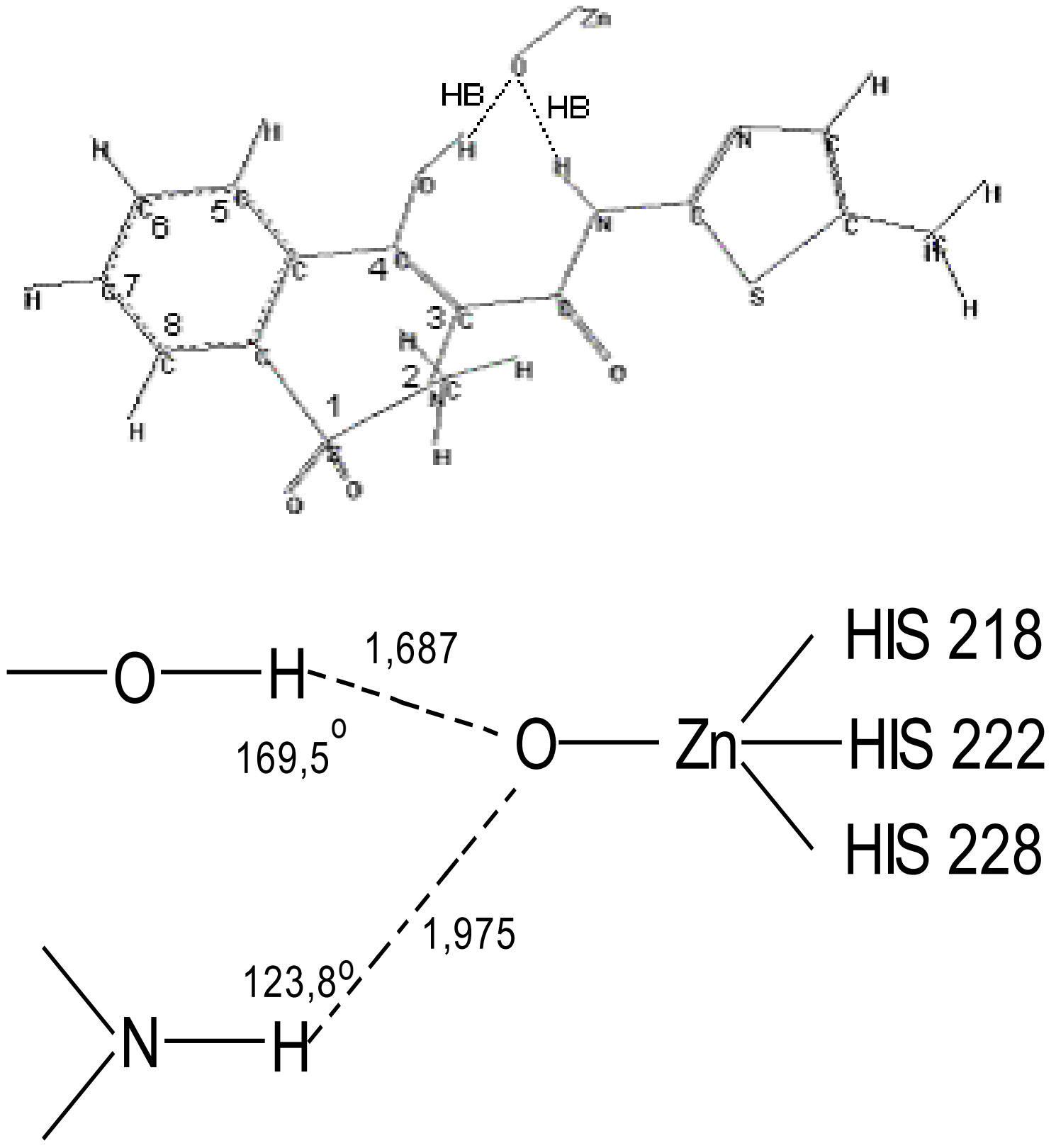
c) Tenoxicam

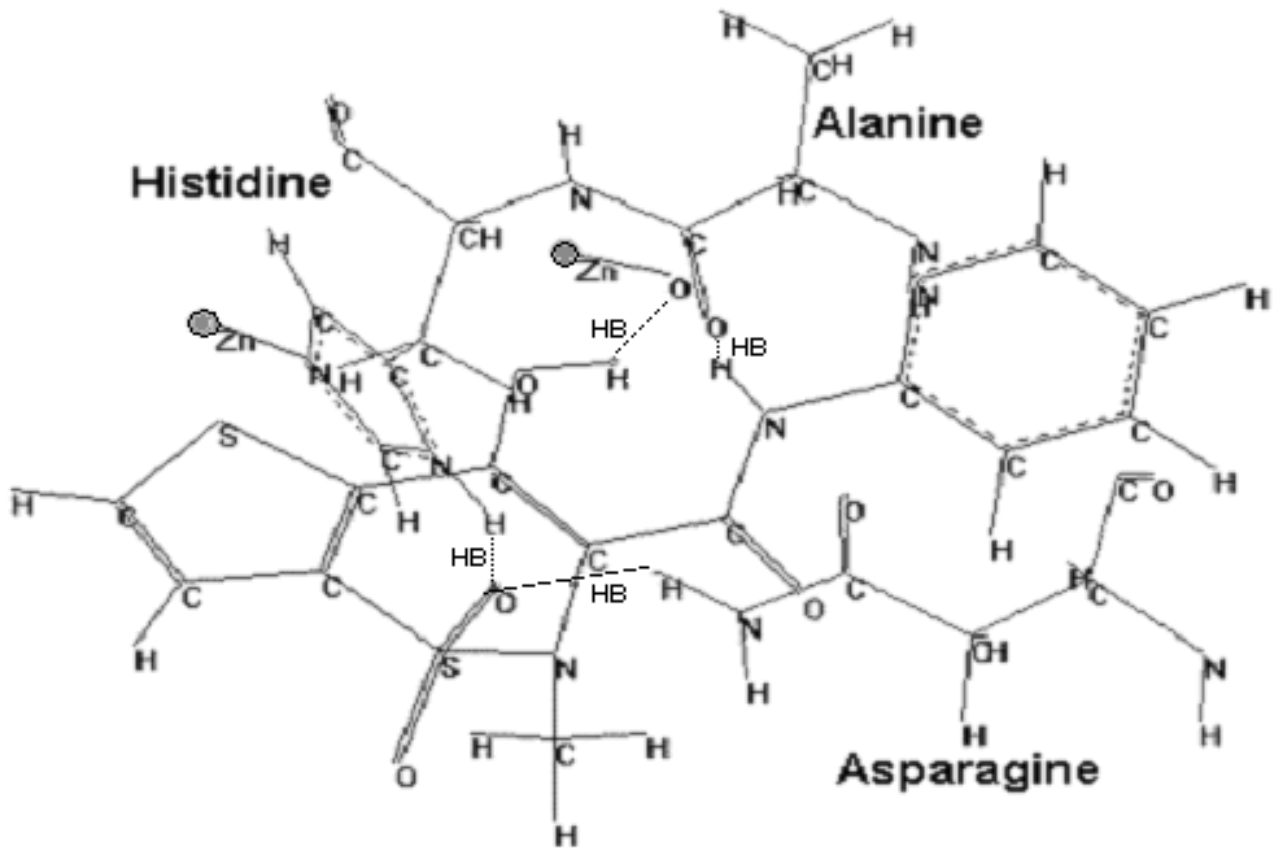

Detail:
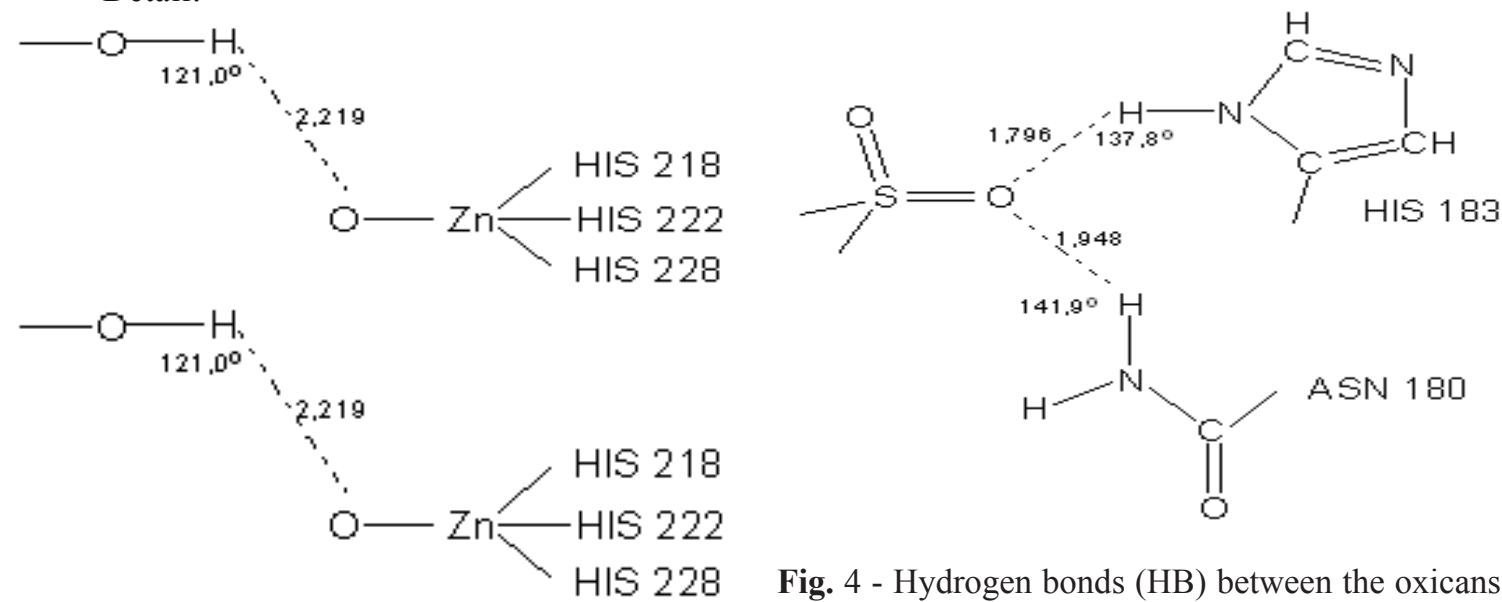

Fig. 4 - Hydrogen bonds (HB) between the oxicans and MMP-1 active site. Distances in ångströms and angles in degrees.

As cited in the introduction section, the $\mathrm{Zn}^{2+}$ involved in the catalytic process coordinates to three residues of histidine and to one molecule of water, through its oxygen. The docking simulation of Piroxicam and Meloxicam with MMP1 showed the formation of two hydrogen bonds between the groups $\mathrm{N}-\mathrm{H}$ and $\mathrm{O}-\mathrm{H}$ of the oxicans 
and the $\mathrm{O}$ coordinated to $\mathrm{Zn}^{2+}$ (fig. 4a, b). For the Tenoxicam the calculation suggested a different interaction schema: first, a hydrogen bond between the $\mathrm{O}-\mathrm{H}$ and $\mathrm{O}-\mathrm{Zn}$, as in the two others oxicans; second, absence of the bond between $\mathrm{N}-\mathrm{H}$ and $\mathrm{O}-\mathrm{Zn}$ (angle and distance unfavorable); third, more three hydrogen bonds involving groups of Tenoxicam and amino acids residues of MMP-1, namely: $\mathrm{N}-\mathrm{H}$ with $\mathrm{O}=\mathrm{C}$ of ALA $182, \mathrm{~S}=\mathrm{O}$ with $\mathrm{H}-\mathrm{N}$ of HIS 183, and $\mathrm{S}=\mathrm{O}$ with $\mathrm{H}-\mathrm{N}$ of ASN 180 (fig. 4c).

The docking calculation between sodium alendronate and MMP-1 indicated the impossibility to form a hydrogen bond between this ligand and the oxygen linked to zinc, confirming the importance of such interaction for the enzyme inhibition, as the alendronate does not inhibit this enzyme. The highest intensity of inhibition of Piroxicam and Meloxicam compared to Tenoxicam also coincides with a weaker interaction of the latter (longer bond and only one) with the oxygen bonded to catalytic zinc. The angle $\mathrm{O}-\mathrm{H} \cdots \cdots \mathrm{O}$ of this hydrogen bond is smaller than the analog for Piroxicam and Meloxicam, which also contributes to the weakening of the bond.

The calculated total bond energies reinforce this conclusion: its absolute value for TenoxicamMMP-1 complex is smaller than for the other two oxicans. Table 1 resumes these comments.

Table 1 - Relation among bond energy, nature of the hydrogen bonds (HB) between the ligands and $\mathrm{Zn}$ environment of MMP-1, and intensity of inhibition of enzyme activity. The greater the length of HB and the more its angle differs from the ideal value of $180^{\circ}$, weaker it is.

\begin{tabular}{|c|c|c|c|c|c|c|}
\hline Ligand (L) & $\begin{array}{c}\begin{array}{c}\text { Number of HB } \\
\text { (Total) }\end{array} \\
\end{array}$ & $\begin{array}{c}\text { Number of } \mathrm{HB} \\
\mathrm{L} \cdots \cdot \mathrm{O}-\mathrm{Zn}\end{array}$ & $\begin{array}{c}\text { Length of } \\
\text { HB }(\AA)\end{array}$ & $\begin{array}{c}\text { Angle of } \\
\text { HB (degree) }\end{array}$ & $\begin{array}{c}\text { Ligand IC50 } \\
(\mu \mathrm{M})\end{array}$ & $\begin{array}{c}\text { Total bond } \\
\text { energy (hartree) }\end{array}$ \\
\hline Piroxicam & 2 & 2 & $\begin{array}{l}2.049 \\
1.726\end{array}$ & $\begin{array}{l}126.5^{\circ} \\
164.3^{\circ}\end{array}$ & 63 & -0.090489 \\
\hline Meloxicam & 2 & 2 & $\begin{array}{l}1.975 \\
1.687\end{array}$ & $\begin{array}{l}123,8^{\circ} \\
169.5^{\circ}\end{array}$ & 66 & -0.090757 \\
\hline Tenoxicam & 4 & 1 & 2.219 & $121.0^{\circ}$ & 91 & -0.064924 \\
\hline Alendronate & 4 & 0 & - & - & activator & -0.022507 \\
\hline
\end{tabular}

Concluding, for the three oxicans, the more important groups for interaction with the human collagenase are the hydroxyl and the secondary amine, binding to the heterocyclic ring and to the carbonyl, respectively. In the three cases the hydroxyl establishes a hydrogen bond with the atom of oxygen linked to catalytic zinc. The amine forms a second hydrogen bond with the same oxygen for Meloxicam and Piroxicam, but this does not occur with Tenoxicam, on account of the inappropriate geometry of the groups involved, particularly a very small N-H-O angle $\left(86.7^{\circ}\right)$. This fact, plus the $\mathrm{O}-\mathrm{H} \cdots . . \mathrm{O}$ bond weaker than the analog ones in the other two oxicans, result in a smaller inhibiting effect of Tenoxicam upon the human collagenase.

Besides the adequate geometry, electronic requirements must be satisfied for the establishment of a hydrogen bond: representing this by A $-\mathrm{H} \cdots \mathrm{B}$, the bond is stronger as more electrone- gative is the atom $\mathrm{A}$ and better electron donor is the atom $\mathrm{B}$. Thus, lower the electronic charge in A (less negative, therefore) and greater in B (more negative), better. For the oxicans, atom $\mathrm{A}$ is represented by the hydroxyl oxygen and by the amine nitrogen. For the three oxicans, electronic partial charge on hydroxyl oxygen varies very little (fig. 5 ), indicating that this property is irrelevant in differentiating the inhibitory effect, here essentially dependent on the geometry. Curiously, the positive charge on the hydroxyl hydrogen is higher in Tenoxicam, which has the less favorable geometry, resulting in a lower inhibiting effect. This indicates that any effort to increase the electron density on the hydroxyl hydrogen of Tenoxicam would be innocuous to intensify its inhibitory effect. The same behavior occurs for the amine hydrogen of the oxicans, whose partial charges vary in the same sense. 


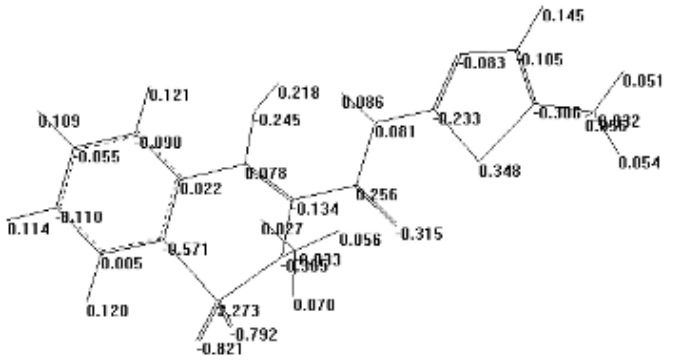

Meloxicam

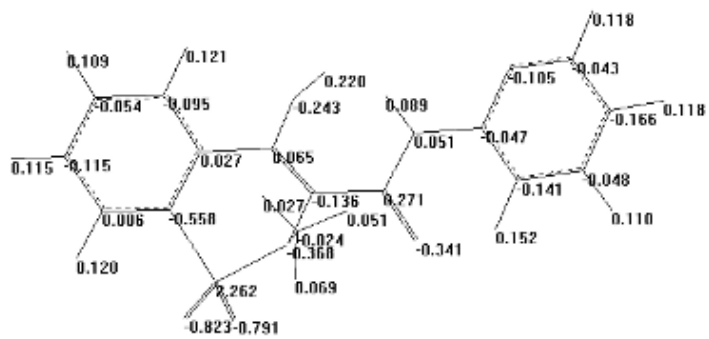

Piroxicam

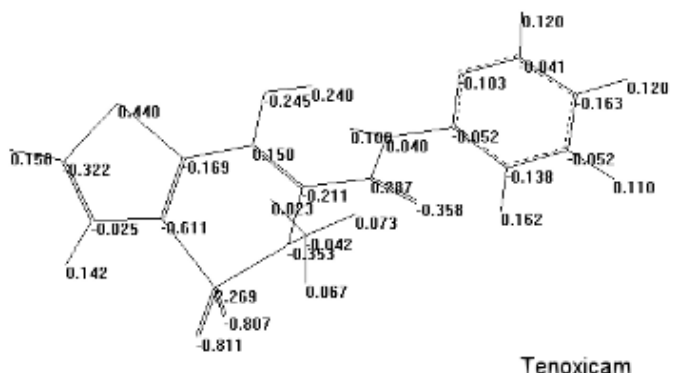

Fig. 5 - Mülliken partial charges for Meloxicam, Piroxicam and Tenoxicam.

In conclusion, among the essayed compounds, only Meloxicam and Piroxicam may be useful as leaders compounds for the search of more potent collagenase inhibitors. Their geometry is correct and a stronger bond with the enzyme may be obtained varying adequately the electronic densities. This could be achieved by appropriate substitutions in different groups of the molecules, capable to reduce the electronic densities on hydroxyl and amine hydrogens. As examples, we calculated the partial charges of the fluorine and nitro-derivatives of Meloxicam and Piroxicam.

First, for Meloxicam, the fluorination of carbon 5 (numeration in fig.4) [35] of the aromatic ring increases the hydroxyl $\mathrm{H}$ partial charge from 0.218 to 0.226 , and the perfluorination of the ring (four fluorine atoms) increases this charge to 0.272 . The amine $\mathrm{H}$ is little affected, provide that the inductive effect spreads little in the carbon chain. Otherwise, in the case of Piroxicam, both mono and perfluorination have no effect on the hydrogen charges. Therefore, it is probable that the fluorination redounds in some increase in the intensity of the hydrogen bond between hydroxyl and enzyme, but only in the case of Meloxicam.

Nitration (mono) of the aromatic ring may occur in the carbon atoms vicinal and not vicinal in relation to the neighboring ring. Such nitration decreases the electron density on positions ortho and para regarding the nitro group, with almost no change in position meta. This behavior results from the strong mesomeric effect [36] generated by this group, as illustrated in the diagram below (Fig. 6).

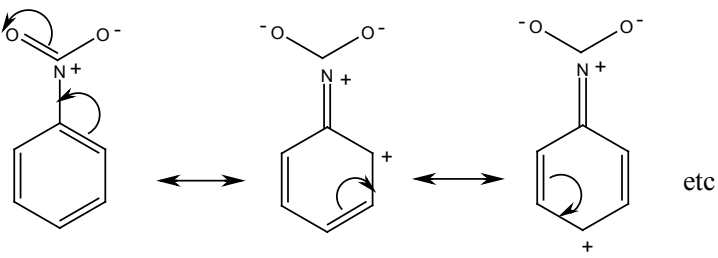

Fig. 6 - Mesomeric effect of nitro group on the benzene ring.

In consequence, the nitration in carbon 5 of Meloxicam and Piroxicam causes great reduction in the electron density of neighbor carbon, while the nitration in position 6 does not influence it. In the Meloxicam, the charge on this carbon changes from 0.022 to 0.182 in the nitro compound in 6 and does not change $(0.020)$ in the nitro compound in 7. In the case of Piroxicam, in the first case the charge goes from 0.027 to 0.185 and in the second to 0.047 . Such change in formal charge in the 5-nitro derivatives also reflects on the carbon 4 , bound to the hydroxyl group, and consequently on the hydroxyl itself. The partial charge rises on carbon 4 in both oxicans, and the hydrogen of the 
hydroxyl group becomes more positive. This is schematized in the figure 7 .

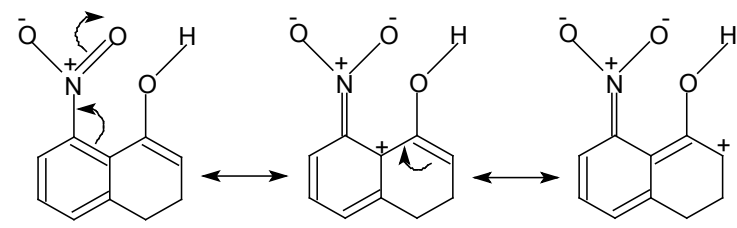

Fig. 7 - Resonance structures in nitrated Meloxicam and Piroxicam.

Greater extension of aromaticity of the benzene ring to the alongside ring in the ortho derivative, on account of electron delocalization extended to him, intensifies the phenolic character of the group $\mathrm{OH}$. Thus, this group becomes more acidic and the $\mathrm{H}$ more likely to form a hydrogen bond with an electron donor center, as the oxygen bond to MMP-1 catalytic Zn. A stronger hydrogen bond should result in stronger enzyme inhibition. Therefore, the 6-nitro-derivatives of Meloxicam and Piroxicam could be promising candidates to inhibitors of human connective tissue collagenase.

Thermodynamics properties - Let us discuss now the effect of the complexation with ligands on the two components of the enzymatic entropy. First, consider the effect on the entropy of hydration of the enzyme. As already discussed, this is increased by disarray of water molecules and their exclusion along the surface that interacts with the ligand. By hypothesis, this area corresponds to half of the surface area of ligand molecule. As seen in table 2, the ratio between the area of the surface of the enzyme that interacts with the ligand and the total area of the enzyme is small, about 3 per cent, and does not vary significantly for the three oxicans. Therefore, the stabilizing effect of the ligand on the entropy of hydration is small. Furthermore, the differences among the areas of water exclusion caused by the different oxicans are negligible, indicating that this effect is irrelevant to explain the difference between the activity of Tenoxicam and the other two oxicans.

Table 2 - Surface area of human collagenase and oxicans, and ratio between the half of ligand surface area and the area of the enzyme.

\begin{tabular}{cccc}
\hline Molecule & Surface area $\left(\AA^{2}\right)$ & Half surface area $\left(\AA^{2}\right)$ & $\begin{array}{c}\text { Ratio } \\
1 / 2 \text { surface area lig. / } \\
\text { surface area MMP1 }\end{array}$ \\
\hline Human collagenase & 8619,19 & - & - \\
Piroxicam & 510,89 & 255,45 & 0,030 \\
Meloxicam & 535,02 & 267,51 & 0,031 \\
Tenoxicam & 504,92 & 252,46 & 0,029 \\
\end{tabular}

The effect of complexation on the conformational entropy of the collagenase will be now analyzed. The results of calculations are summarized in table 3 . We observe that the complexation decreases a little $(<6 \%)$ the conformational entropy of the enzyme. The small decline of entropy resulting from this interaction indicates an increase in the rigidity of lateral chains of some amino acid residues of the collagenase, due to the binding with the ligands. However, the comparative figures between the oxicans do not justify the observed differences on the enzyme activity, once the decrease of the entropy follows the same order of the increase in the inhibiting activity and not the inverse, as expected. 
Table 3 - Calculation of collagenase conformational entropy and their change during complexation.

\begin{tabular}{|c|c|c|c|c|c|}
\hline Molecule & $\begin{array}{l}\text { Total Energy of } \\
\text { the optimized } \\
\text { structure (kcal/ } \\
\text { mol) }\end{array}$ & $\begin{array}{c}\text { Total Energy } \\
\text { after heating } \\
0 \text { to } 300 \mathrm{~K} \\
(\mathrm{kcal} / \mathrm{mol})\end{array}$ & $\begin{array}{c}\text { Entropy (S) } \\
(\mathrm{kcal} / \mathrm{mol} . \mathrm{K})\end{array}$ & $\begin{array}{c}\text { Sum of } \\
\text { entropies of } \\
\text { enzyme and } \\
\text { free ligands }\end{array}$ & $\begin{array}{c}\text { Difference } \\
\left(\mathrm{S}_{\text {sum }}-\mathrm{S}_{\text {complex }}\right)\end{array}$ \\
\hline Human collagenase & - 9859,48 & $-7037,12$ & 11,16 & 一 & 一 \\
\hline Piroxicam & 37,898 & 89,278 & 0,171 & 一 & - \\
\hline Meloxicam & 45,152 & 92,412 & 0,158 & - & - \\
\hline Tenoxicam & 57,229 & 98,187 & 0,137 & - & - \\
\hline Collagenase + piroxicam & $-9473,34$ & $-7471,95$ & 10,66 & 11,33 & 0,67 \\
\hline Collagenase + meloxicam & $-9501,59$ & $-6862,33$ & 10,91 & 11,32 & 0,41 \\
\hline Collagenase + tenoxicam & $-9464,15$ & $-6931,24$ & 10,98 & 11,30 & 0,32 \\
\hline
\end{tabular}

In conclusion, the entropic effect seems to be irrelevant in the interpretation of inhibitory activity of the ligands. Thus, the inhibition of human collagenase by the oxicans is better justified by structurally specific effects, dependent on their structure and charge distribution, and not by the structurally nonspecific ones, as the case of the entropy. This is a desirable outcome: since there is a series of metalloproteinases in the connective matrix, all of them very similar in structure, but with diverse participation in different pathologies, the selectivity of the inhibitor is very important. This selectivity can only be achieved through structurally specific effects, strictly dependent on the geometry and electronic properties of the molecule.

\section{Acknowledgements}

We thank the Fundação de Amparo à Pesquisa do Estado de São Paulo (FAPESP) for the financial support (proc. $\mathrm{n}^{\circ}$ 00/11285-6). 
Resumo: Diferentes substâncias utilizadas como fármacos foram ensaiadas como inibidores da colagenase intersticial humana, também conhecida como metaloprotease $1 \mathrm{da}$ matriz conjuntiva e pela sigla em inglês MMP-1. O estudo foi de natureza experimental e também de simulação computacional. A atividade da colagenase foi quantificada fluorimetricamente, pela reação com um substrato sintético fluorescente, cuja emissão se altera após a hidrólise. A interação colagenase-inibidor foi analisada teoricamente, mediante cálculos de docking. Três das quatro substâncias testadas apresentaram atividade inibidora moderada sobre a colagenase humana.

Palavras-chave: colagenase, MMP-1, metaloproteases humanas, inibidores, ancoragem.

\section{References}

[1] G.J.P. Murphy, G. Murphy, J.J. Reinolds, FEBS 289 (1991) 4.

[2] Browner, M.F.; Smith, W.W.; Castelhano, A.L. Biochemistry 34 (1995) 6602.

[3] Woessner Jr, J.F. FASEB 5 (1991) 2145.

[4] Vallee, B.L.; Auld, D.S. Biochemistry 29 (1990) 5647.

[5] Salowe, S.P.; Marcy, A.I.; Cuca, G.C.; Smith, C.K.; Kopka, I.E.; Hagmann, W.K.; Hermes, J.D. Biochemistry 31 (1992) 4535.

[6] Bode, W.; Reinemer, P.; Huber, R.; Kleine, T.; Schnierer, S.; Tschesche, H. - EMBO J. 13 (1994) 1263.

[7] Borkakoti, N.; Winkler, F.K.; Williams, D.H.; D’Arcy, A.; Broadhurst, M.J.; Brown, P.A. Johnson, W.H.; Murray, E.J. Struct. Biol. 1 (1994) 106.

[8] Lovejoy, B.; Cleasby, A.; Hassell, A.M.; Longlely, K.; Luther, M.A.; Weigl, D.; McGeehan, G.; McElroy, A.B.; Drewry, D.; Lambert, M.H.; Jordan, S.R. Science 263 (1994) 375.

[9] Spurlino, J.C.; Smallwood, A.M.; Carlton, D.D.; Banks, T.M.; Vavra, K.J.; Johnson, J.S.; Cook, E.R.; Falvo, J.; Wahl, R.C.; Pulvino, T.A.; Wendoloski, J.H.; Smith, D.L. Proteins 19 (1994) 98.

[10] Stams, T.; Spurlino, J.C.; Smith, D.L.; Wahl, R.C.; Ho, T.F.; Qoronfleh, M.W.; Banks, T.M.; Rubin, B. Struct. Biol. 1 (1994) 119.

[11] Moy, F.J.; Pisano, M.R.; Chanda, P.K.; Urbano, C.; Killar, L.M.; Sung, L.; Powers, R. J. Biomol. NMR 1 (1997) 9.

[12] Lovejoy, B.; Welch, A.R.; Carr, S.; Luong, C.; Broka, C.; Hendricks, R.T.; Campbell, J.A.; Walker, K.A.; Martin, R.; VanWart, H.; Browner, M.F. Nat. Struct. Biol. 6 (1999) 217.

[13] Jozic, D.; Bourenkov, G.; Lim, N.H.; Visse, R.; Nagase, H.; Bode, W.; Maskos, K. J. Biol. Chem. 280 (2005) 9578.

[14] Gooley, P.R.; Johnson, B.A.; Marcy, A.I.; Cuca, G.C.; Salowe, S.P.; Hagmann, W.K.; Esser, C.K.; Springer, J.P. Biochemistry 32 (1993) 13098.

[15] Gooley, P.R.; O'Connell, J.F.; Marcy, A.I.; Cuca, G.C.; Salowe, S.P.; Bush, B.L.; Hermes, J.D.; Esser, C.K.; Hagmann, W.K.; Springer, J.P.; Johnson, B.A. Struct. Biol. 1 (1994) 111.
[16] Van Doren, S.R.; Kurochkin, A.V.; Hu, W.; Ye, Q.Z.; Johnson, L.L.; Hupe, D.J.; Zuiderweg, E.R. Protein Sci. 4 (1995) 2487.

[17] Gooley, P.R.; O‘Connell, J.F.; Marcy, A.I.; Cuca, G.C.; Axel, M.G.; Caldwell, C.G.; Hagmann,W.K.; Becker, J.W. J. Biomol NMR 7 (1996) 8.

[18] Dhanaraj, V.; Ye, Q.Z.; Johnson, L.L.; Hupe, D.J.; Ortwine, D.F.; Dunbar, J.B., Jr; Rubin, J.R.; Pavlovsky, A.; Humblet, C.; Blundell, T.L. Structure 15 (1996) 375.

[19] Capalonga, A.M.; Alexander, R.S.; Christianson, D.W. J. Biol. Chem. 267 (1992) 19192.

[20] Qing-Xiang, A.S.;1 Meng-Chun, J.; Schwartz, M.A.; Jaye, M.C.; Kleinman, H.K.; Ghaffari, M.A.; Yi-Lin, L. Biochem. Biophys. Res. Commun. 274 (2000) 780.

[21] Schwartz, M.A.; Wart, H. Van. US Patent 9.509.620, 1995.

[22] Teronen, O.; Heikkila, P.; Konttinen, Y.; Laitinen, M.; Salo, T.; Hanemaaijer, R.; Teronen, A.; Sorsa, T. p. 453-465; Barracchini, A.; Franceschini, N.; Minisola, G.; Pantaleoni, G.C.; Di Giulio, A.; Oratore, A.; Amicosante, G. p. 665-666; Llavaneras, A.; Golub, L.M.; Rifkin, B.R.; Heikkilä, P.; Sorsa, T.; Teronen, O.; Salo, T.; Liu, Y.; Ryan, M.E.; Ramamurthy, N.S. p. 671-674; all articles in: Annals of the New York Academy of Sciences, Volume 878, 1999.

[23] Knight, C.G.; Willenbrock, F.; Murphy, G. FEBS Letters 296 (1992) 263.

[24] Lovejoy, B.; Cleasby, A.; Hassell, A.M.; Longlely, K.; Luther, M.A.; Weigl, D.; McGeehan, G.; McElroy, A.B.; Drewry, D.; Lambert, M.H.; Jordan, S.R. Science 263 (1994) 375.

[25] Protein Data Bank, Brookhaven National Laboratory. Structure 1CGL.

[26] CAChe 5.0 User Guide, Fujitsu Systems Business of America, Inc., Beaverton, USA, 2001.

[27] HyperChem., Computational Chemistry, Hypercube Inc., Waterloo, Canada, 1995.

[28] Schrödinger, Inc. First Discovery: Technical notes for version 1.8. Portland, USA, 2001.

[29] Stewart, J.J.P. J. Comput. Chem. 10 (1989) 209.

[30] Cole, C.; Warwicker, J. Protein Science 11 (2002) 2860.

[31] Bodor, N., Gabanyi, C., Wong, J. J. Am. Chem. Soc. 111 (1989) 3783.

[32] Gavezotti, A. J. Am. Chem. Soc. 100 (1983) 5520. 
[33] HuperCube Inc., ChemPlus: extentions for HyperChem, Hypercube Inc., Waterloo, Canada, 1993.

[34] Leite, S.R.A. Eclet. Quim. 33 (2008) 47.

[35] Jayaselli,J.; Cheemala,J.M.S.; Rani D.P.G.; Pal, S. J. Braz. Chem. Soc. 19 (2008) 509.

[36] Ingold, C. K. Structure and Mechanism in Organic Chemistry; Cornell University Press; Ithaca, 1953. 